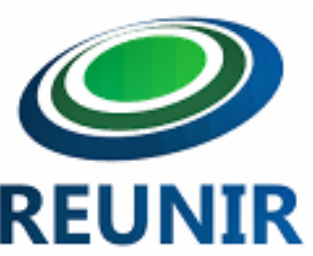

REUNIR:

Revista de Administração,

Ciências Contábeis e

Sustentabilidade

www.reunir.revistas.ufcg.edu.br

ARTIGO ORIGINAL

\title{
Lugares de memória e a nomeação do patrimônio público com nomes de pessoas em Campina Grande - PB/Brasil ${ }^{1}$.
Places of memory and the appointment of public heritage with names of people in Campina Grande - PB/Brazil.

\section{Lugares de memoria y el nombramiento del patrimonio público con nombres de personas en Campina Grande - PB / Brasil.}

Edjane Esmerina Dias da Silva², Amanda Luiza Freire de Almeida ${ }^{3}$

\section{PALAVRAS-CHAVE}

Nomeação;

Patrimônio público;

Direito à Cidade.

\section{KEYWORDS}

Appointment; Public patrimony; Right to the City.
Resumo: De onde vem a prática de nomear o patrimônio público com nomes de pessoas? Que estratégias políticas motivam tal nomeação? Diante dessa curiosidade, observou-se que em Campina Grande, cidade situada no Estado da Paraíba, ruas, praças, bairros e monumentos recebem nomes de pessoas. Ao refletir sobre essas questões partiu-se da hipótese de que essa prática de nomeação oficial do patrimônio por nomes de pessoas se caracteriza como uma estratégia política de apropriação simbólica da coisa pública, uma tática de manutenção de um tipo de cultura política local que provoca como consequência uma violação do direito à cidade como um direito da coletividade. Com a pesquisa tornou-se possível identificar como funciona a cultura política local. Para tanto, foi realizada uma análise discursiva tendo como referência Michel Foucault (2012). Partiu-se de um diálogo teórico com Lefebvre (2001) e Harvey (2014) no direito à cidade; democratização da memória e lugares de memória com Le Goff (2012) e Pierre Nora (1993); alegorias do poder em Carvalho (2002); a dominação masculina e o conceito de habitus com Bourdier (2010) e Perrot (1989), apropriação e artes de fazer em Certeau (1994) e Cultura política, Neto (2012). Como resultado identificou-se que a problematização da prática de nomeação do patrimônio público permite observar uma cultura política local personalista, privatista, masculina e masculinizante, elitista e patrimonialista onde há apropriação da cidade mediante captura simbólica de seu espaço com a denominação de seus logradouros e monumentos.

Abstract: Where does the practice of naming public property with names of people come from? What political strategies motivate such appointment? Faced with this curiosity, it was observed that in Campina Grande, a city located in the State of Paraiba, streets, squares, neighborhoods and monuments are named after people. Reflecting on these questions, it was hypothesized that this practice of naming heritage by the names of people is characterized as a political strategy of symbolic appropriation of the public thing, a tactic of maintaining a type of local political culture that causes consequence of a violation of the right to the city as a right of the

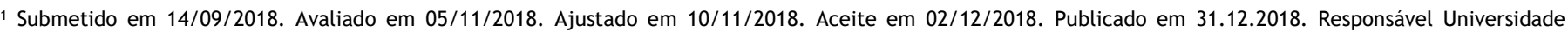
Federal de Campina Grande / UACC / PROFIAP / CCJS / UFCG.

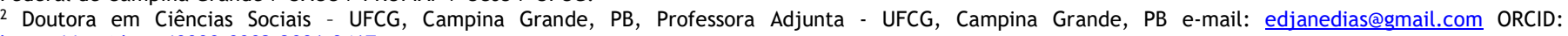
https: / /orcid.org/0000-0002-3096-9467

${ }^{3}$ Graduanda em Engenharia Civil - UFCG, Campina Grande, PB, Brasil. e-mail: amandafreire.eng@outlook.com ORCID: https: //orcid.org/0000-0003-3850-4100
} 
PALABRAS CLAVE Nombramiento; Patrimonio público; Derecho a la ciudad. collectivity. With the research, it became possible to identify how the local political culture works. For that, a discursive analysis was carried out with reference to Michel Foucault (2012). It started with a theoretical dialogue with Lefebvre (2001) and Harvey (2014) in the right to the city; democratization of memory and places of memory with Le Goff (2012) and Pierre Nora (1993); allegories of power in Carvalho (2002); male domination and the concept of habitus with Bourdier (2010) and Perrot (1989), appropriation and arts of making in Certeau (1994) and Political culture, Net 2012). As a result, it was identified that the problematization of the practice of naming the public patrimony allows observing a localist personalistic culture, privates, masculine and masculinizing, elitist and patrimonialist where there is appropriation of the city by means of symbolic capture of its space with the denomination of its public places and monuments.

Resumen: ¿De dónde viene la práctica de nombrar el patrimonio público con nombres de personas? ¿Qué estrategias políticas motivan tal nombramiento? Ante esta curiosidad, se observó que en Campina Grande, ciudad situada en el Estado de Paraíba, calles, plazas, barrios y monumentos reciben nombres de personas. Al reflexionar sobre estas cuestiones se partió de la hipótesis de que esta práctica de nombramiento oficial del patrimonio por nombres de personas se caracteriza como una estrategia política de apropiación simbólica de la cosa pública, una táctica de mantenimiento de un tipo de cultura política local que provoca como una violación del derecho a la ciudad como un derecho de la colectividad. Con la investigación se hizo posible identificar cómo funciona la cultura política local. Para ello, se realizó un análisis discursivo con referencia a Michel Foucault (2012). Se partió de un diálogo teórico con Lefebvre (2001) y Harvey (2014) en el derecho a la ciudad; democratización de la memoria y lugares de memoria con Le Goff (2012) y Pierre Nora (1993); alegorías del poder en Carvalho (2002); la dominación masculina y el concepto de habitus con Bourdier (2010) y Perrot (1989), apropiación y artes de hacer en Certeau (1994) y Cultura política, Neto (2012). Como resultado se identificó que la problematización de la práctica de nombramiento del patrimonio público permite observar una cultura política local personalista, privatista, masculina y masculinizante, elitista y patrimonialista donde hay apropiación de la ciudad mediante captura simbólica de su espacio con la denominación de sus logradouros y monumentos. 
Introdução

Este artigo é resultado de pesquisas desenvolvidas nos anos de 2016 e 2017 pelo Grupo de Pesquisa, Ensino e Extensão em Direitos Humanos - GRUPEDIH da Universidade Federal de Campina Grande. 0 primeiro percurso de pesquisa intitulado como Política, Monumentos e Memória: Uma História Patriarcal \& Masculinizante (2016) teve como objeto de pesquisa a memória das mulheres cristalizadas nos monumentos políticos da cidade de Campina Grande - PB. 0 resultado observado foi a ausência das mulheres nas narrativas presentes nos monumentos políticos da cidade,

Uma segunda inserção no campo da pesquisa sobre a memória envolveu as políticas públicas de gestão do patrimônio cultural a partir do próprio ato de nomeação dos monumentos e logradouros por nomes de pessoas (2017). 0 problema de pesquisa buscou investigar quais as estratégias de poder que marcam a cultura política local a partir do ato de nomeação do nome de praças, monumentos e logradouros por nomes de pessoas.

Assim, visando (des) construir a narrativa histórica oficial da cidade na busca de democratização da memória e da garantia do direito à cidade como direitos humanos seguiuse problematizando os lugares de memória a partir da prática de nomeação do patrimônio público da cidade de Campina Grande por nomes de pessoas. A hipótese de que a lógica cultural de nomeação reproduz maneiras de fazer política no espaço local, consolidando uma cultura política privatista, personalista, patrimonialista, masculina e masculinizante, marcada pela apropriação simbólica dos espaços públicos.

Quanto aos procedimentos de pesquisa foi realizada análise documental, segundo Marconi \& Lakatos (2017), caracteriza-se por tomar como fonte de coleta de dados documentos, escritos ou não, que podem ser arquivos públicos, particulares ou fontes estatísticas. Também aparecem elementos de pesquisa de campo que segundo Lopes (2016) visa um apanhado geral da situação estrutural a partir um comparativo feito entre monumentos históricopolíticos da cidade através de registros fotográficos.

$\mathrm{Na}$ análise dos documentos como monumentos como orienta Le Goff (2012), o discurso não está descolado das relações de poder e saber que marcam o ato de nomeação do patrimônio público por nomes de pessoas. Para tanto, foi realizada uma análise discursiva tendo como referência Michel Foucault (2012).

No percurso da pesquisa foram realizados debates teóricos tendo como referências os seguintes estudos: Lefebvre (2001) e Harvey (2014) no que fundamenta o estudo do direito à cidade; nos estudos da democratização e lugares de memória destaca-se Le Goff (2012) e Pierre Nora (1993); alegorias do poder em Carvalho (2002); a dominação masculina e o conceito de habitus com Bourdier (2010) e Perrot (1989); apropriação e artes de fazer em Certeau (1994) e Cultura política com Neto (2012).

\section{Direito à cidade e a memória como campo de pesquisa}

Não pode haver direito à cidade se a memória coletiva não estiver preservada em seus monumentos. Com isso, a própria maneira de representação do patrimônio urbano e, por consequência, os próprios elementos considerados como patrimônio, são históricos e, portanto, disputáveis social e politicamente.
Ao problematizar as relações de poder presentes no processo de instituição dos monumentos públicos urbanos da cidade de Campina Grande busca-se ampliar o campo de pesquisa em direito à cidade incluindo a temática da memória construída pela narrativa oficial, problematizando de maneira entender as várias relações de poder que a produziram e sacralizaram determinados personagens como protagonista da história e que, por sua vez, excluíram a memória coletiva.

A cidade como campo dividido entre o espaço público e privado começa a ser desenhado e seus conflitos vivenciados nas tramas da política citadina e dos sujeitos protagonizam a cidade como obra, como definiu Lefebvre (2015). O francês Henri Lefebvre (2015). O autor foi um filósofo e sociólogo marxista que realizou estudos importantes referentes à cidade como obra em 0 direito à cidade, publicada em 1968. Segundo ele:

Se há uma produção da cidade, e das relaçães sociais
na cidade, é uma produção e reprodução de seres
humanos por seres humanos, mais do que uma
produção de objetos. A cidade tem uma história; ela
é a obra de uma história (...). Houve na história uma
produção das cidades assim como houve produção de
conhecimentos, de cultura, de obras de artes e de
civilização, assim como houve, bem entendido,
produção de bens materiais e de objetos prático-
sensíveis. Essas modalidades da produção não se
dissociam, sem que se tenha o direito de confundi-
las reduzindo as diferenças. (Lefebvre, 2015, p.52-
53)

Baseado nas ideias desse autor os monumentos podem ser analisados como a tentativa de uma narrativa sobre a história da cidade de Campina Grande como produto das relações dos grupos sociais, uma imagem interessada da cidade que busca cristalizar a identidade política marcada pela figura do homem empreendedor, comerciante, industrial, latifundiário, banqueiro e militar.

Outro autor importante na discussão do direito à cidade é o geógrafo britânico David Harvey (2012) que contribuiu na concepção de que o direito à cidade é um dos direitos humanos. A obra que marca a discussão é Rebel Cities: From the right to the city to the urban revolution publicada em 2012. Segundo ele a própria definição do 'direito' é objeto de uma luta, e essa luta deve ser concomitante com a luta por materializá-la. (Harvey, 2012, p.20). Dessa forma, a (des)construção da memória é um ato político de tentar reconstituir ou pelo menos tentar mostrar como foi construída a narrativa da história da cidade de Campina Grande sacralizada nos monumentos das praças da cidade.

\section{Lugares de memória e direito à cidade}

$\mathrm{Na}$ discussão acerca da produção da memória na narrativa da história da cidade convém dialogar com autores da terceira geração da Escola dos Annales, movimento historiográfico francês que se destaca por incorporar métodos das ciências sociais à história em meados das décadas de 70 a 80 , e que vai possibilitar um estudo diferenciado da história política a partir de um diálogo com a antropologia. Entre os historiadores destaca-se o francês Jacques Le Goff (2012) que dentre outros estudos dedicou-se à antropologia histórica medieval. Para Le Goff (2012), a 
história - forma científica da memória coletiva - é resultado de uma construção, sendo que os materiais que a imortalizam são o documento e o monumento. o que sobrevive não é o conjunto daquilo que existiu no passado, mas uma escolha efetuada quer pelas forças que operam no desenvolvimento temporal do mundo e da humanidade, quer pelos que se dedicam à ciência do passado e do tempo que passa; os próprios historiadores.

Em sua obra História e Memória (1988), o autor aponta conceitos importantes para entendermos os monumentos políticos como objetos que documentam uma narrativa histórica. A dualidade monumento/documento indica que o documento é fruto de uma construção histórica, ou seja, reflete um momento e a mentalidade de uma determinada sociedade. Nessa perspectiva o documento também é um monumento, ou seja, a cristalização de toda uma relação de poder entre grupos que querem se perpetuar na memória histórica da cidade. Entende-se por monumento essa memória registrada nos bustos, estátuas, acervos fotográficos e nomes de logradouros.

É importante destacar que somente na chamada Nova História, fruto do movimento francês da Escola dos Analles, no início do século XX, a memória coletiva se tornou objeto de reflexão para os historiadores. Nessa linha, segundo Le Goff (2012), a democratização da memória social e os silêncios da história são aspectos relevantes para a compreensão da memória dos grupos e comunidades: Cabe, com efeito, aos profissionais científicos da memória, antropólogos, historiadores, jornalistas, sociólogos, fazer luta pela democratização da memória social, um dos imperativos prioritários da sua objetividade científica (LE GOFF, 2012, p. 457). É preciso entender que a sacralização da memória em bustos, estátuas, acervos fotográficos e nomes de logradouros é uma ação política, e que há uma construção social de uma identidade que se torna legítima ao passo em que o sujeito aceita o discurso e se localiza no contexto histórico. Trata-se da construção de uma identidade coibidora de atitudes, ou seja, que não permite que outros sujeitos se localizem como protagonistas do fazer político.

Embora a discussão sobre democratização da memória tenha introduzido uma questão dos estudos sociais na historiografia no início do século $X X$, não foi suficiente para promover um debate profundo sobre a inserção das mulheres na História. Esse rompimento do silêncio que cerca as mulheres, para Michelle Perrot, só foi possível nas décadas de 60 a 70 do século XX. Michelle Perrot é uma historiadora e professora emérita da Universidade Paris VII que realizou estudos relacionados aos personagens que a historiografia até então deixou à margem dos acontecimentos, sobretudo as mulheres, com destaque ao silêncio presente em suas falas públicas e atuações políticas, espaços que estavam restritos aos homens no contexto da França no século XIX. Em Práticas da memória feminina (1989) Perrot elenca como objeto de reflexão o próprio esquecimento para entender a memória coletiva das mulheres na política: No teatro da memória, as mulheres são sombras tênues. A narrativa histórica tradicional reserva-lhes pouco espaço, justamente na medida em que privilegia a cena pública - a política, a guerra- onde elas pouco aparecem. (Perrot, 1989, v.9 p. 9)

Atribui-se historicamente ao papel da mulher na sociedade as condições biológicas do comportamento humano. Nessa perspectiva ela seria unicamente responsável pela reprodução da espécie. Cabe à mulher passar aos seus descendentes valores que constituirão a formação cidadã. Para Pierre Bourdieu (2010), sociólogo e filósofo francês, a naturalização do papel da mulher na sociedade é fruto de mecanismos estruturais que buscaram legitimar a dominação masculina, algo que pode ser historicizado e que se consolidou progressivamente de tal maneira na sociedade que perpassa por detalhes do cotidiano. Esses mecanismos constituem uma violência simbólica; forma de violência sem coerção física que se apoia no reconhecimento de uma imposição determinada e induz o indivíduo a se posicionar no espaço social seguindo critérios e padrões do discurso dominante. Seriam as instituições, e não apenas as famílias, que melhor reproduzem essa dominação e contribuem para a formação do habitus, ou seja, uma lei social que foi incorporada ao longo da história.

Se existe, portanto, uma dominação masculina, existe a ação masculinizante, e é essa que conta a história política de Campina Grande através dos seus monumentos. Inseridas num espaço que foi, durante décadas, constituído como masculino, a mulher assume na política o mesmo papel que foi acordado entre os que a faziam, ou seja, como a nossa subjetividade é produzida socialmente, então os padrões masculinos se subjetivaram. Não é o fato de biologicamente ser homem ou mulher, mas o agir político que tem um habitus, atitudes de um modus operandi caracterizado socialmente como masculino. Na obra Langage et pouvoir symbolique publicada em 1989, Bourdieu (2011) introduz o poder simbólico como o poder de constituir o dado pela enunciação, de fazer crer a partir de um código de valores e de uma linguagem que distinguem os dominantes dos dominados a partir da construção de uma cultura, ou do que ele chama de capital cultural onde um determinado grupo possui o domínio de um código linguístico e de valores instituídos entre eles.

Outro autor que também fez parte da Escola dos Analles e que contribui na discussão sobre a memória coletiva é Pierre Nora (1993), um historiador francês conhecido pelos seus trabalhos sobre a memória, identidade francesa e o papel da historiografia. Na obra Les Lieux de mémoire (1984), uma coleção editada em sete tomos sobre a história da França, Nora desenvolve o conceito de lugares de memória ou lugares onde a memória se cristaliza. A organização dos tomos da sua obra se deu na ocasião em que se discutia o desaparecimento da memória nacional francesa e a necessidade de ser feito um inventário dos lugares onde ela se encontrava presente. Toda a discussão de Nora é influenciada pelos estudos do sociólogo francês da escola durkheimiana Maurice Halbwachs (1990), autor da obra A memória coletiva publicada em 1950, uma obra pioneira sobre os estudos da memória social. A questão central dessa obra consiste em afirmar que a memória individual existe sempre a partir da memória coletiva, posto que todas as lembranças são construídas no interior de um grupo. Para Halbwachs (1990), a memória coletiva é espontânea e cabe à história incorporar as lembranças à medida que fossem deixando de existir os grupos que as sustentavam. Nora (1993), no entanto, entende que a memória deixou de existir justamente porque passou a ser reivindicada pelo discurso histórico, e se não há mais memória, o que resta agora são os lugares de memória. Esses lugares de memória a que Nora se refere, no entanto, são lugares oficiais, uma história 
estabelecida em geral pelo poder público. Caberia à história enquanto operação intelectual (des)construir essa memória.

A instituição dos lugares de memória pelo poder público tem como foco uma narrativa oficial que conta a história dos personagens heroicos nacionais. Cada vez mais a democratização nas representações monumentais históricas se faz necessária. Sujeitos que se sentem historicamente excluídos da narrativa histórica oficial que é apresentada por esses lugares: logradouros públicos com nomes de generais, empresários e coronéis, museus e monumentos que representam determinados grupos de destaque, ou seja, a narrativa oficial não assume a discussão sobre as desigualdades que marcam a nossa formação histórica social.

Murilo de Carvalho (1990), cientista político e historiador brasileiro tem se dedicado nos últimos anos ao estudo da construção da cidadania no Brasil. Em A formação das Almas (1990), ele defende que em virtude do processo de agitação republicana e a deflagração da República no Brasil não terem tido apoio popular na ocasião em que aconteceram foi gerada uma discussão entre as elites em torno da importância do papel do estado ser legitimado na construção da República. Isso contribui para pensar a construção da política e da identidade através dos símbolos e monumentos. Para o autor o extravasamento das visões republicanas para o meio popular interessava às elites como forma de legitimação do poder e isso teria sido feito mediante sinais universais, de leitura fácil, como as imagens, as alegorias, os símbolos e os mitos. Tratava-se de uma batalha para construir o imaginário popular republicano. Segundo Carvalho (2002), a massa popular assistiu bestealizada ao processo de Proclamação da República, e tão pouco estiveram as mulheres protagonizando o processo. Desde os primórdios a elite política era formada por homens. A mulher, se pública, era prostituta. Não só as mulheres não participavam como não era considerado próprio que elas participassem (Carvalho, 2002, p.92).

Michel de Certeau, um sacerdote jesuíta rebelde e erudito, distinguiu-se por procurar compreender os modos como os grupos sociais usam os códigos e lugares que thes são impostos, produzindo práticas microscópicas dispersas e criativas. Certeau (1994) constata, de forma sutil, que os gestos estratégicos das instituições sociais, uma configuração urbana ou imposições estatais, são apropriados de modo tático, astucioso e inventivo, as artes de fazer dos praticantes, as operações astuciosas e clandestinas.

A partir do diálogo com os autores supracitados e dos estudos da cultura política desenvolvida acerca da Paraíba, principalmente da história republicana, seguiu-se uma influência da nova história política e dos seus pressupostos teórico-metodológicos norteadores, segundo Cittadino (2012) foram eles: o poder é visto na sua multiplicidade de expressão - da apropriação dos espaços políticos pelos grupos familiares oligárquicos ao papel desempenhado por líderes políticos no processo de reordenamento do Estado; os conceitos de imaginário e mito político conferem densidade e adquirem especial relevo ao serem aplicados nas análises dos grandes vultos da nossa história, atores sociais diversos adquirem voz e passam a explicar a sua compreensão e vivência do poder político em diferentes contextos.

Assim o conceito de cultura política como sendo a compreensão das ações políticas a partir do entendimento dos valores, dos sentimentos e das tradições, ou seja, do político explicado pela cultura, acrescentou-se a contribuição no conceito de Certeau como algo relacionado a maneira de fazer pois a maneira de fazer passa pela cultura local e a forma como o código é subvertido, ou seja, apropriado. A partir da (des) construção da maneira de fazer demonstra-se o uso privatista, personalista e patrimonialista de ocupação da cidade nos tempos modernos que, seguindo os estudos de Alves (2012), demonstrou como a política local esteve, durante as décadas iniciais da República Velha, marcada por uma disputa política familiar dicotômica que ao longo dos anos foi reestruturada e modificada em suas nomenclaturas de acordo com os novos líderes que alcançam a liderança dos grupos políticos locais, mas mantendo suas bases eleitorais e fontes de articulação política, ou seja, atuando sob a perspectiva patrimonialista.

\section{Elementos metodológicos da pesquisa}

Para que os objetivos desta pesquisa fossem atingidos contou-se com uma proposta teórico-metodológica construída com base na contribuição de alguns autores. Há elementos de análise documental e análise do discurso histórico que segundo Marconi e Lakatos (2017), caracterizase por tomar como fonte de coleta de dados documentos, escritos ou não, que podem ser arquivos públicos, particulares ou fontes estatísticas. Também aparecem elementos de pesquisa de campo que segundo Lopes (2016) visa um apanhado geral da situação estrutural a partir de um comparativo entre monumentos histórico-políticos da cidade através de registros fotográficos.

No processo de análise da narrativa histórico-política presente nos monumentos e projetos de leis que instituem nomes para lugares públicos da cidade, convém colocar em discussão a forma como os discursos produzem os lugares de memória. Na obra A Arqueologia do Saber (2012), o filósofo Michel Foucault contribui ao discutir a possibilidade de haver uma unidade no discurso a partir de regras da formação discursiva. 0 autor analisou as regras que permitem a emergência de um discurso ao longo do tempo ou as suas condições de produção, tornando-se visíveis as relações de poder no ato comunicativo. Observa-se uma regularidade no discurso a partir da análise de uma série de enunciados que compõem um objeto em cada temporalidade. Dentro desses discursos existem enunciados semelhantes em conceitos, escolhas temáticas e estratégias, uma regularidade que diremos se tratar de uma formação discursiva. É preciso enxergar que não basta o discurso como um texto, mas enquanto um conjunto de enunciados regidos por regras descritas a partir de valores e tradições de um grupo dominante.

\section{Direitos humanos à cidade e à memória: o lugar das mulheres}

Quais espaços foram reservados às mulheres na narrativa histórica oficial da cidade de Campina Grande?

A instalação da ferrovia na cidade no início do século $X X$ culminou com o auge do processamento e escoamento do algodão iniciando o ciclo de ouro branco em Campina Grande. Registra-se que nessa época a mulher pobre, no ciclo produtivo do algodão, ocupava a posição de algodoeira adquirindo a inserção no mundo do trabalho, mas não no espaço publico. A privilegiada localização da cidade fez dela 
um empório comercial por onde o produto vindo de toda região passava. Esse cenário marcado pelo sucesso do chamado ouro branco que compreendeu ao período de 1920 a 1940 possibilitou o surgimento de comerciantes no ramo de algodão e de sisal, empresários de prensagem e banqueiros; os chamados coronéis do algodão. É esse grupo que convenciona a forma de se fazer política na cidade.

Um segundo lugar que nesse contexto foi reservado à mulher na narrativa histórica da cidade foi o espaço da boémia em lugares como o Eldorado. Em 1937, quando Campina Grande já era conhecida como a Liverpool Brasileira por ser a segunda maior exportadora de algodão depois de Liverpool na Inglaterra, foi construído o Eldorado, um dos símbolos do sucesso comercial da cidade. A repercussão gerada pelo ciclo do algodão atraiu investidores de toda a região, principalmente da capital Recife. O Eldorado era um cassino com sala de jogos, dançarinas e exibições de artistas que ficou famoso por receber os coronéis do algodão, políticos e boêmios que formavam a socialite campinense. Antônio Pereira de Morais no seu livro vi, ouvi e senti explica que o Eldorado tinha na sua estrutura apartamentos para mulheres e dependência para jogos e diversões.

Segundo destaca a narrativa da edição especial Campina Grande 150 anos à frente publicada pelo Jornal da Paraíba em 2014, muitas das mulheres que ocupavam o espaço da boémia vinham de Recife, Rio de Janeiro ou muitas oriundas do sertão da Paraíba, e se destinavam à cidade ainda quando adolescentes para trabalhar nos prostíbulos.

Nos espaços públicos de diversão, o regulamento propunha recato e silencio às meretrizes pobres. Valorizava-se o ideal da mulher doméstica, contida, que não exprime suas emoções, que controla as pulsões corporais e o desejo. A prostituta era tão reificada pelos investimentos estratégicos do poder no controle de sua aparência quanto nas relações sexuais com os fregueses. 0 papel a ser representado era o não-papel, a não existência, para não ser percebida pela multidão e não se destacar de outras mulheres, silenciosas como ela. (Rago, 2008, p.136)

Retrata uma imagem da cidade que destaca o lugar da mulher na memória histórica ligada a sexualidade. Ora é retratada como santa, ora pecadora. A imagem de santa reservado ao espaço doméstico e excluindo-a do espaço público, e a imagem de puta presente nos espaços de boémia.

$\mathrm{Na}$ pesquisa de campo quanto aos monumentos, constatou-se que não há na cidade bustos ou estátuas com homenagem a personalidades femininas, enquanto existem catorze monumentos com homenagem a homens que estiveram ligados à política a partir de uma trajetória que tem início na atividade comercial. 0 que existem são representações estilísticas da mulher (Figura 01) que a referencia a partir do simbolismo de mãe, sensível, cuidadora e terna. A imagem à esquerda exibe uma escultura que marca a nomeação da praça como Praça da Ternura, construída em 1964 na gestão do Prefeito Newton Rique. Destaca-se a ideia do feminino construído pelo masculino, uma prática muito recorrente no período da ditadura militar a partir da criação de valores morais para o ideário de família tradicional. Nesse sentido, a relação de gênero perpassa a construção da cidade.

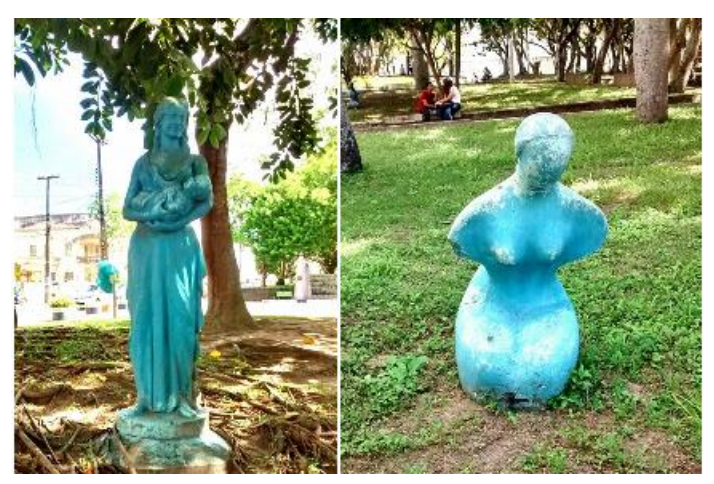

Figura 01: À esquerda escultura em homenagem às mães de Campina Grande construída na década de 60, à direita representação estilística da mulher esculturada no início da década de 90

Fonte: (Grupedih, 2018)

\section{A nomeação do patrimônio público de Campina Grande - PB}

No dia 6 de abril de 1790, Campina Grande passou a ser chamada oficialmente de Vila Nova da Rainha, em homenagem à Rainha Dona Maria I. Apesar da mudança de nome, os habitantes locais continuaram a chamar o lugar de Campina Grande, e somente em textos oficiais e formais o nome Vila Nova da Rainha era utilizado. A nomeação da cidade como Rainha da Borborema marca 0 ato de apropriação atribuindo nomes femininos construídos pelo masculino. No imagético deste discurso, a Rainha é subserviente e intitulada como posse como veremos na análise de textos oficiais a seguir. São projetos de lei que justificam a homenagem em alguns lugares de memória da cidade. Constatamos que existem na cidade catorze monumentos histórico-políticos que homenageiam homens dentre os quais comerciantes, políticos, latifundiários e militares. As mulheres não aparecem nesses monumentos ficando reservada a elas a memória presente em acervos fotográficos de museus e documentos pessoais.

$\mathrm{Na}$ busca por elementos que fortaleçam a tese de que há na narrativa histórica oficial de Campina Grande-PB indícios de uma cultura política personalista, privatista, masculina e masculinizante, elitista e patrimonialista, onde há apropriação da cidade mediante captura simbólica de seu espaço com a denominação de seus logradouros e monumentos, também foi realizada uma pesquisa documental dos projetos de leis arquivados na Câmara Municipal de Campina Grande que dispõem sobre a construção de bustos, monumentos e estátuas. Estes projetos de leis possibilitam observar quem são os personagens homenageados. Foi realizado um trabalho de leitura buscando identificar no texto jurídico desses projetos de leis indícios de uma tentativa de construção identitária política e cidadã local. A seguir constam 6 (seis) projetos e em destaque elementos que produzem uma regularidade discursiva, ou seja, regras que possibilitam a formação do discurso dominante e que se repete na estrutura das leis que dão nome à coisa pública da cidade. Podemos destacar que esse conjunto de enunciados que possibilitam a existência do discurso presente no texto jurídico é escolhido de forma estratégica e têm a função de instituir uma identidade 
política subjetivada pelos grupos que detém o poder local. Esses elementos são: a intenção de perpetuar a memória sacralizada nos monumentos, a construção de uma identidade política aliada à origem do sujeito em uma família tradicional local, a trajetória do sujeito que passa pela atividade comercial, industrial ou empreendedora antes de ingressar na carreira política, o perfil do sujeito como generoso e modesto, e o seu Amor pela cidade manifestado através da realização do Trabalho.

O primeiro documento a destacar é o Projeto de Lei de $\mathrm{n}^{\circ} 75$ aprovado em 9 de outubro de 1979 que dispõe sobre a ereção do busto (Figura 02) de Isaías Souza do Ó, latifundiário e empresário. 0 busto foi colocado na praça que tem o nome do seu pai Juvino Souza do Ó, prefeito de Campina Grande em 1923. Observa-se no projeto de lei que as despesas correram por conta dos amigos e parentes, o que indica um ato de apropriação do espaço público em que a homenagem é privada e familiar. Outro elemento que se destaca é a trajetória do homenageado: iniciou suas atividades comerciais como empregado da firma Comércio de Algodão de Campina Grande, depois associou-se na firma João Vasconcelos \& Cia, e mais tarde na Companhia e Comércio de Prensagem de Algodão, de quem foi seu diretor. Essa empresa foi uma das maiores na Paraíba na exportação de Sisal e Algodão (...). Nota-se que a memória da cidade é produzida com destaque para a atividade comercial onde aparecem os chamados Coronéis do Algodão, um grupo elitista e privilegiado por seu lugar na sociedade. 0 sujeito é referenciado segundo uma narrativa histórica que personifica na imagem do homem comerciante e político a identidade dos heróis que construíram a história de Campina Grande.
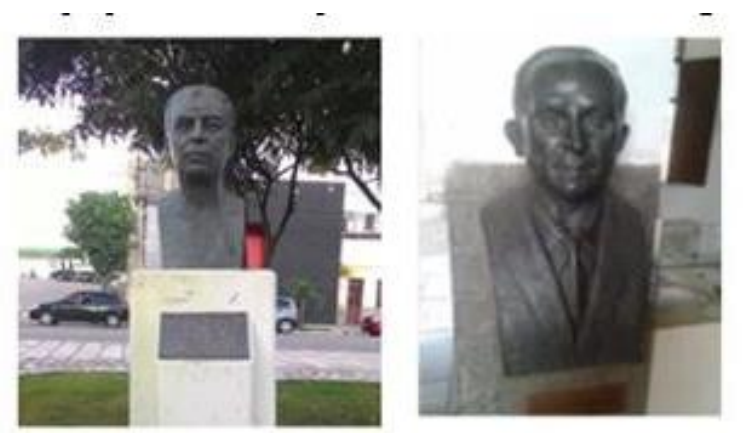

Figura 02 - Homenagem a João Vasconcellos à esquerda, e Isaías de Sousa à direita.

Fonte: (Grupedih, 2018)

Um segundo trecho que faz parte da construção dessa identidade na política local evidencia o lugar na família, ou seja, a árvore genealógica: O senhor Izaias Souza do Ó, casado com Alice Souza do Ó, deixou a seus filhos Edvaldo Souza do Ó, Eudes Souza do Ó, Edson Souza do Ó, José Souza do Ó, Djalma Souza do Ó e Salete Souza do Ó o exemplo de sua existência pautado dentro dos conceitos que norteou a conduta e personalidade do Varão Juvino Souza do Ó, exemplo que sempre orientou seus filhos a permanecerem seguindo. Fica claro no trecho um ideal tradicional familiar em que o homem (Varão) é o progenitor do qual descendem as qualidades de seus filhos.

Existe ainda outra característica presente no projeto de lei que é a exaltação de uma determinada modéstia. Destaca- se do trecho a seguir: A sua maneira de ser, sem vaidades, sem orgulhos, com muito amor, não só no contato com seus filhos e amigos, mas também no trato dos negócios, tratando a todos com finura e dedicação, fez com que todos o admirasse-lhe dedicando estima e reconhecimento digno a um verdadeiro Pai. Além do destaque para a modéstia como sendo parte de uma dada personalidade política local, podemos destacar ainda que há uma referência ao comerciante como um Pai, ou seja, constrói-se a figura do herói.

O projeto de lei finaliza com a seguinte declaração: (...) perpetuaremos no Bronze, no Efigio, a memória de um dos mais belos exemplos de existência terrena, deixaremos registrado nesta casa, para sua história, para a juventude do amanhã um exemplo a seguir. Izaias de Souza do Ó permanece vida, foi amor, foi trabalho e dedicação e hoje é inspiração em que tudo isto reunido transformou-o em um dos homens que todos nos orgulhamos em tê-lo conhecido e privado com honra na galeria dos que privaram da sua amizade. Fica claro no trecho apresentado a intenção de perpetuar essa memória, de fazê-la parte constituinte da memória e de uma cultura política local. Outros dois elementos valem ser comentados: o amor e o trabalho. Veremos em outros projetos de lei que o fator trabalho é referência no fazer político, bem como o amor à cidade em que Campina Grande é subjetivada como feminina (a Rainha da Borborema), são fatores recorrentes na construção dos memoriais.

0 segundo documento analisado foi o Projeto de Lei $n^{\circ}$ 25 aprovado em 9 de maio de 1975 que estabelece o nome de João Vasconcelos para uma praça construída no parque da Estação velha onde também foi eregido um busto em sua homenagem (Figura 02). Destaca-se novamente os mesmos elementos do projeto anterior como parte de uma regularidade discursiva que tem a estratégia de construir uma identidade do sujeito para os modos de fazer da política local. Na justificativa da homenagem a João Vasconcelos temos o seguinte trecho: Onde atuou empresarial e socialmente foi tudo quanto um homem de bem pode desejar ser: conselheiro municipal na gestão do saudoso Lafayete Cavalcanti; fundador da associação comercial de Campina Grande (...) presidente da Cia comércio e prensagem de Algodão; presidente da Sibrasil - indústria sisaleira do Brasil S/A (...) cargos que ocupou com o objetivo de trabalhar e ser útil à sociedade e à pátria. Existe neste enunciado uma concepção do desejo do homem de bem que seria o de ser parte de um grupo da elite cuja trajetória inicia no ramo comercial e industrial.

Um terceiro documento analisado foi o projeto de Lei $\mathrm{n}^{\circ} 67$ aprovado em 30 de setembro de 1971 que denomina de Praça João Rique o logradouro público construído entre a confluência das ruas João Pessoa, João Suassuna e Marquês do Herval. Também dispõe sobre a construção de uma estátua (Figura 03) e de um monumento em homenagem a João Rique. Podemos destacar o seguinte trecho da Justificativa do projeto de lei: 0 trabalho é instrumento gerador de progresso e o elemento básico e fecundador de todas as riquezas existentes no globo terrestre, não somente no seu aspecto material, como, sobretudo, no cultural e espiritual dos povos. O Sr. João Rique Ferreira foi, em vida, pela fé e pelo trabalho, um exemplo edificante que merece ser seguido por todos aqueles que desejam 0 
desenvolvimento, e que somente pelo trabalho poderão conseguir e ver materializados os seus objetivos. Destaca-se novamente o elemento trabalho como uma característica presente na personalidade do sujeito protagonista na política.

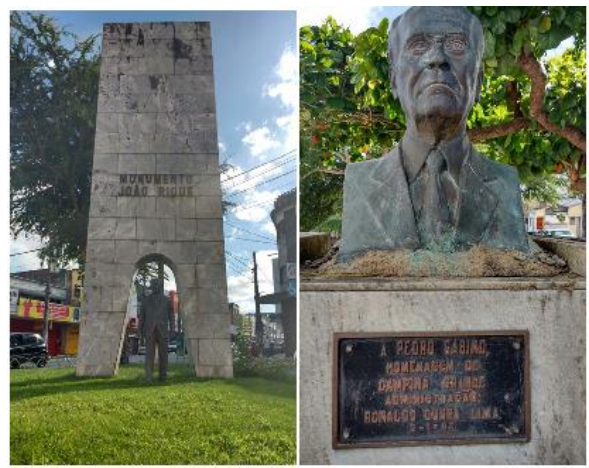

Figura 03 - À esquerda estátua em homenagem ao banqueiro João Rique. À direita busto em homenagem ao comerciante Pedro Sabino

Fonte: (Grupedih, 2018).

Trata-se de se instituir o poder dado pela enunciação, de fazer crer a partir de um código de valores que distingue os dominantes dos dominados. Outro trecho que vale destacar é o seguinte: 0 gênio criador do Sr. João Rique fez com que, em pouco tempo, os seus empreendimentos crescessem tanto que já não era mais possível conte-los apenas em Campina Grande (...) consubstanciada no desenvolvimento pleno das empresas por ele criadas através, principalmente, do Banco Industrial de Campina Grande, que projetou o nome de nossa cidade através do país inteiro, como símbolo da operosidade da nossa gente e do dinamismo da nossa cidade. Percebe-se também que é criada uma imagem de cidade do progresso econômico, no entanto é sabido que um pequeno grupo desfrutava dos privilégios sociais, e aos populares restavam os bairros periféricos e as profissões subalternas. Tratou-se de se instituir uma ordem social.

Há ainda outro trecho relevante na justificativa dessa lei: Pai extremoso, católico praticante, sentimental, ardoso defensor dos interesses coletivos de Campina Grande (...) Ninguém fez mais por Campina, até agora, que esse vulto singular de homem probo, generoso e progressista que foi João Rique Ferreira. Há uma referência a seu papel na família como pai exemplar, e a partir deste conjunto de atribuições ele se constitui no homem íntegro e modesto cujo Seu nome deverá, pois, ficar perpetuado no bronze, para que as gerações futuras lembrem-se dele como se escudadas estivessem num indestrutível escuto de estímulo e de incentivo para as futuras caminhadas em favor do engrandecimento desta terra. Está presente a estratégia de tornar esse lugar de memória um símbolo com a função pedagógica de orientar os cidadãos campinenses para dada identidade política e cultural. Destaca-se ainda o trecho: Seus filhos the seguirão o exemplo através do trabalho e da bondade que se estampavam pelas suas virtudes nos gestos largos de generosidade e de amor a Campina Grande e seu povo. Nota-se que mais uma vez o texto jurídico traz os elementos trabalho e amor que já se mostram recorrentes nos projetos vistos até aqui. Estes são enunciados que tratam de construir os valores que permeia o modus operandi da política local e a construção de uma cidade edificada por homens que são protagonistas do seu desenvolvimento.

0 quarto documento analisado foi o Projeto de Lei $n^{\circ} 73$ aprovado no dia 17 de fevereiro do 1984 que faz denominação da Praça Vereador Pedro Sabino de Farias situada no bairro São José. Nesta praça também foi implantado um busto da referida personalidade, o qual será doado por seus familiares, conforme a Figura 03. Recorre-se, mais uma vez, à prática de instituir uma memória privada e familiar a lugares públicos. Outra questão que se repete está presente no seguinte trecho: o projeto tenta eternizar a memória de um cidadão que, com notória atuação na área comercial, social e política de Campina Grande, ofereceu todo seu trabalho e dinamismo em prol do seu desenvolvimento. Trata-se da construção de um mesmo ideário identitário político em que nota-se o trabalho e a atuação comercial como regras de constituição desses sujeitos, bem, como a função de perpetuar essa memória. Cabe ainda analisar o seguinte trecho: Pedro Sabino de Farias, componente de tradicional família do Município de Campina Grande, durante a sua longa existência, teve destacada atuação na vida comercial, social e política desta cidade, sendo muito tempo no período áureo do comércio do algodão e depois do sisal um dos grandes comerciantes desses ramos de negócio. Posteriormente, ingressou na vida pública, quando foi eleito por várias legislaturas vereador junto à casa Félix Araújo. Pode-se destacar o seu lugar na família tradicional como elemento importante e a sua trajetória até chegar na vida pública ao passar primeiro pela profissão de comerciante e empresário, como aconteceu com vários outros políticos da cidade cuja narrativa histórica elenca como homens públicos conceituados e dignos dos lugares de memória da cidade.

0 quinto documento analisado é o Projeto de Lei $n^{\circ} 55$ aprovado no dia 17 de fevereiro de 1964 que dispõe sobre a construção de uma estátua em homenagem a Argemiro de Figueiredo (Figura 04). Há na introdução da lei o seguinte enunciado: a perpetuação em bronze de homens públicos que se imortalizaram pelos serviços prestados à terra natal é costume que reflete a gratidão daqueles que colheram os frutos de seus devotamentos. Campina Grande não ocuparia a posição de liderança que hoje ocupa no nordeste brasileiro, se não fosse a obra inconteste do saneamento feito pelo ilustre campinense Argemiro de Figueiredo. Nota-se, além da função pedagógica de sacralizar no monumento a figura do herói, a concepção de que Campina Grande é uma obra cuja memória de sua construção é privada, e não coletiva. Todo mérito é reservado aos sujeitos da política. Vale destacar ainda o investimento público para a construção desta homenagem como aparece no Art. $2^{\circ}$ desta lei em que enuncia-se que para ocorrer com as despesas decorrentes da presente lei, fica o chefe do Executivo igualmente autorizado a abrir o crédito especial necessário. Vale salientar que o lugar escolhido para a referida estátua é importante como dito no trecho a seguir: 0 senador campinense faz jus à grande homenagem que o transportará, definitivamente, para a imortalidade, perpetualizando-se no bronze em uma das principais praças públicas de sua terra natal. Destaca-se o fato de que a homenagem foi feita numa praça central de grande visibilidade, o que reforça a função pedagógica e estratégica do monumento.

Não diferente dos outros projetos de lei, também 
constrói uma trajetória política pautada na atividade comercial do sujeito: incentivou a produção de algodão no Estado, alcançando índices fabulosos na sua época; introduziu o sisal na Paraíba, aumentando as suas fontes de riqueza; adquiriu o campo de experimentação de Caratuba (...) em muito colaborando, pelas suas medidas governamentais, para que Campina Grande se transformasse na segunda praça comercial de algodão do mundo, posto que ostentou até alguns anos. 0 sujeito é reverenciado por ser responsável pela produção e sucesso do algodão na cidade, uma memória privatista e personalista do apogeu do produto, quando sabemos que catadores, carregadores do algodão, carregadores de água, entre outros diversos grupos sociais contribuíram no processo de construção da cultura do algodão na cidade. Reaparece ainda nesta lei a ideia de genealogia e lugar na família tradicional como fator importante na construção deste perfil político: (...) um pai amantíssimo, exemplar e apaixonado pelos seus filhos, construindo para a posteridade uma família ilustre, que somente honra trará à Paraíba. A figura do pai exemplar e dedicado é constituinte dos códigos de valores que constroem a ideia de família tradicional.

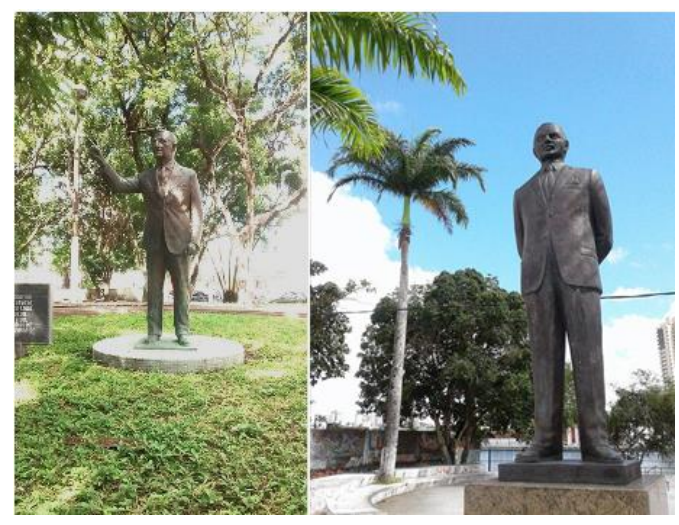

Figura 04 - À esquerda estátua em homenagem ao Ruralista Argemiro de Figueiredo, à direta estátua do militar Vergniaud Wanderley

Fonte: (Grupedih, 2018).

O Sexto documento analisado foi o Projeto de Lei $n^{\circ} 109$ aprovado no dia 30 de março de 2004 que denomina de Parque Vergniaud Wanderley toda a área urbanizada que contorna o Açude Velho. Trata-se de uma renomeação de um espaço público em que há uma personificação e a privatização da memória ao passo que ficou liberada a colocação por parte da família do homenageado, um busto do Ex-Prefeito Vergniaud Wanderley (Figura 04). A justificativa do projeto de lei para esta homenagem introduz também o elemento da modéstia na personalidade do sujeito da seguinte forma: A Paraíba perdeu na tarde de quinta-feira, ultima um dos seus filhos de grande projeção, apesar de simples, modesto, sem artificialismo, sem facúndia, despreocupado em ser e parecer “estrela", Vergniaud Wanderley, foi de Prefeito de Campina Grande, a ministro do Tribunal de Contas da União, do qual foi presidente por 4 (quatro) vezes, e Senador da República. É curioso como toda a trajetória política dos sujeitos citados até aqui passam pelos mesmos elementos. Em outro momento do texto também aparece a questão da genealogia familiar e do ingresso no comércio: Vergniaud Borborema Wanderley, nasceu em Campina Grande, aos onze dias do Mês de agosto de 1905, filho do Coronel Vigolvino Pereira Monteiro Wanderley, membro das destacadas famílias Dantas e Wanderley, originário do alto Sertão da Paraibano, que transferiu-se para esta cidade, ingressando no comércio e na política, participando do Conselho Municipal de 1909, do qual foi presidente. Nota-se o lugar familiar de uma elite de destaque na região, bem como o ingresso no comércio e na política local passando de pai para filho. É atribuído a Vergniaud Wanderley o mérito por ter sido responsável pela reforma urbana da cidade entre 1940 e 1945. Podemos fazer ainda algumas considerações sobre o segundo trecho deste projeto de lei: Em entrevista concedida ao renomado Jornalista Ronaldo Dinoá, sobre o motivo da Revolução Urbana, respondeu que: "Foi o desejo de ver a cidade passar de um simples Burgo a uma Metrópole". Enfrentando as resistências com obstinação e energia, não dando ouvido às ameaças por parte daqueles que se julgavam prejudicados, fez cumprir uma Lei existente e não aplicada anteriormente, sobre o gabarito dos prédios do centro da cidade, desapropriando, comprando e construindo a tal ponto que o chamavam de impetuoso, "SOU UM HOMEM DE DIREITO QUE EM SI MESMO ENCERRA A IDEIA DE FORÇA, SEM A QUAL, NO DIZER DE “HERING”, TRANSFORMAR-SE-IA NA IMPOTÊNCIA DA LEl”. Nota-se nas próprias palavras do Prefeito, que a reforma urbana da cidade foi realizada sob a luz do poder e pelo uso da força. Houve a abertura da Avenida Floriano Peixoto com a demolição de casas e o processo de segregação social que marcaram uma política de higienização do centro da cidade. As pessoas foram obrigadas a se estabelecerem na periferia da cidade onde não havia serviços públicos básicos.

Vale ainda destacar um poema posto no fim deste Projeto de Lei e escrito por um dos vereadores autores que relatam a homenagem a Wanderley: Obrigado a todos, despeço-me com uma ode há minha querida Campina Grande, a grande, tão grande, que já nasceu Rainha. Pode ser de todos, mas para todo o sempre será minha. Grande e perene, pelos filhos concebidos, grande pela ação dos pioneiros, dentre eles, os Tropeiros da Borborema. Grande pelos tempos idos, e vividos. Sentimento maior, que inspetou a este humilde e singelo poema. Fica evidente no texto a subjetivação da Cidade como feminina, como Rainha e mãe daqueles que estão aptos para a governarem, para tomarem posse e a instituírem como minha cidade. Homens que seguem a mesma trajetória familiar, profissional e política, e seguindo critérios e padrões de um discurso dominante constroem uma cultura política masculina e masculinizante, e é isto o que conta a história política de Campina Grande através dos seus monumentos.

\section{Considerações finais}

Configura-se, portanto a tese segundo a qual a cultura política repercute uma lógica privatista, personalista e que busca legitimar a ocupação simbólica da cidade por parte de determinados grupos que se perpetuam no poder. Uma estratégia política do poder local segundo uma dominação simbólica do espaço da cidade. Uma cultura política local masculina e masculinizante que produz subjetividades 
marcadas pela apropriação privatista da cidade em que o sujeito que está a frente do poder se coloque como dono e titular do direito decisório sobre as posições coletivas que constituem os conflitos por direito no espaço da cidade. A ideia de apropriação ajuda a pensar a propriedade como algo além da concepção material da coisa, ou dos direitos a ela atribuídos, ou seja, como algo presente nos lugares de memória. Uma cultura política que marca a gestão do patrimônio cultural e do ato de nomeação dos nomes de praças e logradouros com nomes de pessoas uma ação privatista da coisa pública. Uma prática que se refaz na modernidade advinda de um processo de colonização e dominação das terras do além-mar.

\section{Referências}

BOURDIEU, P. (2010). A dominação masculina. 9 ed. Rio de janeiro: Bertrand Brasil.

BOURDIEU, P. (2011). O poder simbólico. 15 ed. Rio de Janeiro: Bertrand Brasil.

CARVALHO, J. M. de. (2002). A formação das almas: o imaginário da república no Brasil. São Paulo: Companhia de letras.

CERTEAU, M. (1994). A invenção do cotidiano. Rio de Janeiro: Vozes.

CITTADINO, M. (2012). Apresentação. in: NETO, Faustino Teatino Cavalcante et al. Cultura e Poder Político na Paraíba republicana. João Pessoa: Editora Universitária - UFPB.

Foucault, M. (2012). A arqueologia do Saber. 8 ed. Rio de Janeiro: Forense universitária.

GARCIA, F. Campina (Empreendedora) Grande (nos Desafios). Jornal da Paraíba, Campina Grande, p. 2, 31 ago. 2014.

HALBWACHS, M. (1990). A memória coletiva. 2 ed. São Paulo: Vértice, 1990.

HARVEY, D. (2014). Cidades Rebeldes: Do direito à cidade à revolução urbana. São Paulo: Martins fontes.

JÚNIOR, J. A. de L.; LIRA, A. N. da C. (2012). Retratos de Campina Grande: Um século em imagens urbanas. Campina Grande: UFCG.

LEFEBVRE, H. (2001). O direito à cidade. São Paulo: Centauro.

LE GOFF, J. (2012). História e Memória. 6 ed. Campinas: Editora Unicamp.

LOPES, J. (2006). O fazer do trabalho científico em ciências sociais aplicadas. Recife: Editora Universitária da UFPE.

MARCONI, M. de A.; LAKATOS, E. M. (2017). Fundamentos de Metodologia Científica. $8^{a}$ ed. São Paulo: Atlas.

NORA, P. (1993). Entre memória e história: A problemática dos lugares. Revista Projeto História, São Paulo, v.10, p. 0728, dez.

PERROT, M. (1989). Práticas da memória feminina. Revista Brasileira de História, São Paulo, v. 9, n. 18, pp. 09-18, ago.89/set. 89 .

RAGO, M. (2008). Os prazeres da noite: Prostituição e códigos da sexualidade feminina em São Paulo, 1890-1930. $2^{\text {a }}$ ed. São Paulo: Paz e terra.

MORAES, A. P. de. (1985). Vi Ouvi e Senti - Crônicas da Vida Campinense e Outras Narrativas. Campina Grande: Campina Grande. 